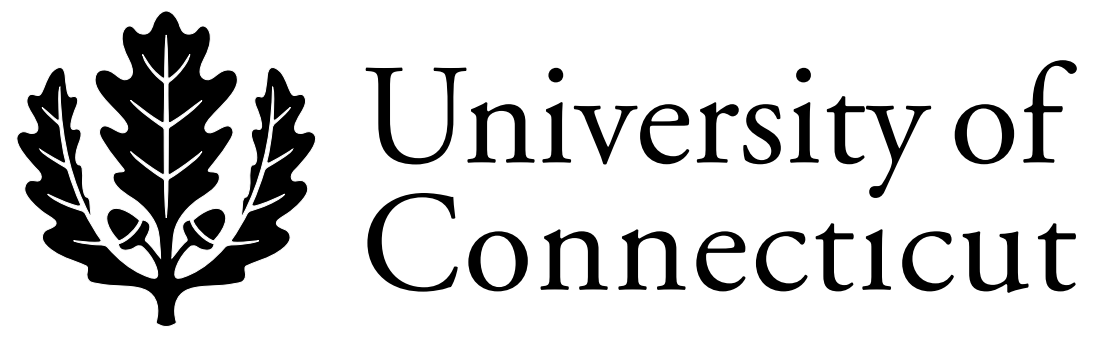

Department of Economics Working Paper Series

Punishing the Innocent along with the Guilty: The Economics of Individual versus Group Punishment

Thomas J. Miceli

University of Connecticut

Kathleen Segerson

University of Connecticut

Working Paper 2004-37

October 2004

341 Mansfield Road, Unit 1063

Storrs, CT 06269-1063

Phone: (860) 486-3022

Fax: (860) 486-4463

http://www.econ.uconn.edu/ 


\begin{abstract}
Standard models of law enforcement involve the apprehension and punishment of a single suspect, but in many contexts, punishment is actually imposed on an entire group known to contain the offender. The advantages of .group punishment. are that the offender is punished with certainty and detection costs are saved. The disadvantage is that innocent individuals are punished. We compare individual and group punishment when social welfare depends on fairness, and when it depends on deterrence. We show that group punishment may dominate in the former case if the detection technology is ineffective but never in the latter case. We discuss our results in the context of several examples.
\end{abstract}

Journal of Economic Literature Classification: K14, K42

Keywords: Group punishment, Law enforcement

We acknowledge the insightful comments and suggestions of Nuno Garoupa and Steven Shavell. 


\section{Punishing the Innocent along with the Guilty: The Economics of Individual versus Group Punishment}

\section{Introduction}

In standard economic models of law enforcement, the chief objective is first to identify, and then punish, the offender. ${ }^{1}$ However, there are many enforcement contexts in which the identity of the offender is uncertain, but he is known to be a member of a well-defined group. Examples include a class prankster, a terrorist who is known to be a member of a particular group or citizen of a certain country, and a polluter who is known to be located within a particular geographic region. Under an "individual punishment" strategy, the enforcement authority invests some resources in apprehending a suspect from this group and then imposes a sanction (perhaps wrongly) on him. However, an alternative punishment strategy is possible: namely, sanction all members of the group. Examples of this sort of "group punishment" include punishing the entire class for the actions of a prankster, sanctioning countries that harbor terrorists, imposing liability on a group of firms for a spill caused by one of them, and, in primitive societies, retaliating against an entire family or clan for the actions of one of its members.

In this paper we examine the conditions under which group punishment is preferred over individual punishment. The benefits of group punishment include certain punishment of the offender and reduced detection costs, while the chief drawback is the cost associated with wrongful punishment of the innocent. To our knowledge, the

\footnotetext{
${ }^{1}$ See, e.g., Polinsky and Shavell (2000a) for a survey of this large literature, which originated with Becker (1968).
} 
economics literature on law enforcement has not systematically examined this question. ${ }^{2}$ There is, however, a related literature on "group incentives," primarily in the context of industrial organization and team production, where the threat of group penalties is used to prevent shirking when the effort of team members is unobservable. ${ }^{3}$ Similar schemes have been proposed for pollution control when the contribution of individual firms is unobservable. ${ }^{4}$ The current model differs from these contexts in several ways. First, they do not explicitly compare individual and group enforcement strategies. Second, they do not ordinarily assume that there is a single offender. Instead, all workers are potential shirkers and all firms are potential polluters. Thus, the decision of whether or not to be an "offender" is made simultaneously by all members of the group, and, if all are identical, all make the same decision (i.e., all are innocent or all are guilty). In contrast, we assume there is a single offender who in effect "hides out" in a group of innocent individuals.

In comparing individual and group punishment, we consider two different measures of social welfare. One depends on the ex post fairness of sanctions- that is, "fitting the punishment to the crime"-while the other depends on deterrence. (The costs of enforcement and of punishing innocent individuals enter both versions.) Most economic models of crime focus only on deterrence, though some have also incorporated concerns about fairness. ${ }^{5}$ We consider both objectives because we believe that both are relevant for understanding actual punishment strategies; indeed, we show that the particular objective matters when evaluating the choice between individual and group

\footnotetext{
${ }^{2}$ But see Levmore (1995a,b) for informal discussions of many of the issues addressed here as well as numerous examples of group punishment.

${ }^{3}$ See, e.g., Holmstrom (1982), Rasmusen (1987), and Varian (1990).

${ }^{4}$ See Segerson (1988), Xepapadeas (1991), and Govindasamy, Herriges, and Shogren (1994).
} 
punishment. Moreover, the results are somewhat surprising. A priori, one might expect that group punishment would be preferred when deterrence is the goal (since more individuals face punishment), while individual punishment would be preferred when fairness is the goal (since fewer innocent individuals are punished). However, our results are in stark contrast to this. In particular, we show that, when punishment is random, group punishment is preferred (if any punishment is desirable) when fairness is the goal, while the two punishment schemes are equally desirable when deterrence is the goal. When the enforcer can invest in detection, then individual punishment will always be preferred under the deterrence goal, while the ranking of the two approaches under the fairness objective will depend on the accuracy of the detection technology. The explanation for these surprising results lies in the endogenous choice of the fine and investment in detection under the two strategies. As it turns out, the conditions under which we find group punishment to be preferred are especially descriptive of ancient societies when group punishment was more pervasive than in modern law enforcement. ${ }^{6}$

The paper is organized as follows. Section 2 lays out the basic model. Sections 3 then analyzes the fairness version of the model, while Section 4 considers deterrence. Section 5 examines several extensions of the basic model. Section 6 discusses various examples of group punishment, from both ancient and modern law, in light of the model. Finally, Section 7 concludes.

\section{The Basic Model}

\footnotetext{
${ }^{5}$ See Miceli (1991) and Polinsky and Shavell (2000b).

${ }^{6}$ See, for example, Posner (1983), especially Chapters 7 and 8.
} 
Consider the following scenario. A single risk neutral individual has committed an illegal act but his identity is unknown. ${ }^{7}$ However, he is known to be a member of a group of size $n>1 .^{8}$ That is, $n$ is defined to be the smallest group of which the offender is known to be a member. The enforcer considers two punishment strategies. Under individual punishment, the enforcer devotes resources to identifying a single suspect who is then sanctioned. Under group punishment, in contrast, the enforcer imposes a uniform sanction on all members of the group. We focus initially on monetary sanctions (fines) but consider non-monetary sanctions in the discussion of extensions.

In comparing these punishment strategies, we consider two alternative social goals regarding punishment. The first assumes that fairness of the sanction is the primary measure of social welfare. This reflects the notion that the actual imposition of punishment occurs after an offense has been committed and a suspect has been apprehended. At that point, all considerations of deterrence of the offense in question are irrelevant, leaving fairness in the treatment of the suspect as the primary concern. This objective, as reflected by the notion of proportionality between punishment and crime, has a long history in human society and is especially descriptive of primitive law enforcement (Posner, 1983: Chapter 8). We then turn to the more conventional goal of deterrence, which requires the enforcer to be able to precommit to imposing a particular sanction regardless of any possible appearance of unfairness after the fact. Under both objectives, we also consider the cost of wrongful punishment, primarily because this is the most important objection to the use of group punishment.

The formal model makes use of the following notation:

\footnotetext{
${ }^{7}$ In Section 5.4 we note the impact of different assumptions about the offender's risk preference.
} 
$F_{I}=$ fine imposed under individual punishment;

$F_{G}=$ fine imposed on all members of the group under group punishment;

$p=$ probability that the individual who is apprehended and punished under individual punishment is the true offender;

$c(p, n)=$ cost of apprehension, $c_{p}>0, c_{p p}>0, c_{n}>0, c_{p n}>0$;

$\sigma=\quad$ scaling factor that reflects the social cost of imposing a $\$ 1$ fine on an innocent individual under either punishment strategy.

We introduce additional notation specific to the alternative versions of the model as necessary below. The characteristics of the cost of apprehension function reflect the assumption that an increase in the group size makes it costlier, both overall and at the margin, to detect the offender. In deriving the optimal enforcement strategy under both versions of the model, we initially treat the probability of apprehension as exogenous (in which case $c(p, n)$ is a fixed cost) and derive the optimal fines. We then extend the model to allow an optimal choice of $p$ as well.

\section{Fairness is the Goal}

We begin by comparing individual and group punishment when social welfare depends on the ex post fairness of the sanction. Thus, the enforcer takes as given the fact that the offense has been committed and seeks to impose the most appropriate punishment. Most commonly, this implies a proportionality between the harm caused

\footnotetext{
${ }^{8}$ We assume throughout that $n$ is exogenous. See Levmore (1995a, pp. 1580-1582) for a discussion of how group punishment might affects people's decisions about whether to join a group.
} 
and the punishment imposed. ${ }^{9}$ (Although deterrence is not an explicit goal, we note the implications of the different punishment strategies for deterrence below.)

To capture the welfare benefits associated with fairness of the sanction, we define:

$$
B(F)=\text { social benefit of imposing a fine of } F \text { on the true offender. }{ }^{10}
$$

We assume that $B(F)$ is a single-peaked function that is maximized at a unique fine, $F^{*}$, which represents the optimal ex post sanction given the nature of the offense. Thus, $B>0$ for $F<F^{*}, B^{\prime}<0$ for $F>F^{*}, B^{\prime}\left(F^{*}\right)=0, B^{\prime \prime}<0$, and $B(0)=0 .{ }^{11}$

Using this notation, we can write social welfare under the individual punishment strategy as follows: ${ }^{12}$

$$
S B_{I}=p B\left(F_{I}\right)-(1-p) \sigma F_{I}-c(p, n)
$$

where, as noted above, the term $(1-p) \sigma F_{I}$ reflects the expected cost of false punishment. ${ }^{13}$ Similarly, social welfare under group punishment is

$$
S B_{G}=B\left(F_{G}\right)-(n-1) \sigma F_{G}
$$

In comparing these expressions, note that the benefit of punishment is realized with certainty under group punishment, whereas it is only realized with probability $p$ under individual punishment. This advantage of group punishment is only achieved, however, at the expense of higher error costs. This represents the fundamental trade-off in the current model.

\footnotetext{
${ }^{9}$ See, for example, Levmore (1995a, p. 1595) and Wittman (1974).

${ }^{10}$ The "proportionality norm" suggests that that $B$ is also a function of the harm caused by the offense. Since we treat this harm as fixed, we suppress this dependence.

${ }^{11}$ This specification follows Polinsky and Shavell $(2000 \mathrm{~b})$. The fact that $B(0)=0$ implies that there is no utility or disutility from imposing a fine of zero.

${ }^{12}$ Note that the gain to the offender and the harm from the offense are not included here since they are sunk at the time the punishment decision is made. We will introduce them below in the discussion of deterrence ${ }^{13}$ Consideration of this cost was first introduced into the economic model of crime by Harris (1970). Also see Miceli (1991).
} 


\subsection{The Optimal Strategy when $p$ is Fixed}

We begin our comparison of the two punishment strategies by considering the case where the probability of apprehending the true offender under individual punishment, $p$, is fixed. We first derive the optimal fines under each strategy, and then compare the resulting social benefits.

The first order condition defining $F_{I}^{*}$ is given by

$$
p B^{\prime}\left(F_{I}\right)-(1-p) \sigma=0,
$$

or

$$
B^{\prime}\left(F_{I}\right)=\left(\frac{1-p}{p}\right) \sigma .
$$

It follows that $F_{I}^{*}<F^{*}$ for $p<1$ and $\sigma>0$, where $F^{*}$, recall, is the fine that maximizes $B(F)$. This reflects the fact that increasing $F$ imposes greater error costs at the margin when detection is imperfect. However, $\partial F_{I}^{*} / \partial p>0$, implying that as detection improves, the optimal fine under individual punishment increases.

An interesting special case is $p=1 / n$, which reflects a situation where an individual is randomly chosen from the group and punished. Suppose, for example, that the enforcer has no ability to gather information about the offender's identity and members of the group are reluctant to reveal it. Thus, this case is perhaps most reflective of small, close-knit groups, but it could also describe large societies in which an offender can become anonymous. Since no detection effort is required to carry out random punishment, $c(1 / n, n) \equiv 0$. Further, note that in this case (3) becomes

$$
B^{\prime}\left(F_{I}\right)=(n-1) \sigma .
$$


Now consider group punishment. The condition defining the optimal fine, $F_{G}{ }^{*}$, is given by

$$
B^{\prime}\left(F_{G}\right)=(n-1) \sigma
$$

which is identical to (4). We can therefore state the following result regarding the optimal fines under the two punishment strategies:

Proposition 1: When $p$ is fixed $(p<1), F_{G} *<F_{I} * F^{*}$ for $p>1 / n$, but $F_{G}{ }^{*}=F_{I} *$ for $p=1 / n$.

Generally, the optimal fine is higher under individual punishment because marginal error costs are lower. However, when individual punishment is randomly imposed, marginal error costs are the same under the two strategies and hence, the optimal fines are the same.

In order to compare the strategies, substitute the optimal values of $F_{I}$ and $F_{G}$ into (1) and (2) to obtain:

$$
\begin{aligned}
& S B_{I}^{*}=p B\left(F_{I}^{*}\right)-(1-p) \sigma F_{I}^{*}-c(p, n) \\
& S B_{G} *=B\left(F_{G}^{*}\right)-(n-1) \sigma F_{G} * .
\end{aligned}
$$

For the case where $p=1 / n,(6)$ becomes

$$
S B_{I}^{*}=\left[B\left(F_{I}^{*}\right)-(n-1) \sigma F_{I}^{*}\right] / n=S B_{G}^{*} / n,
$$

where, recall, $c(1 / n, n)=0$. Further, the fact that $F_{I} *=F_{G} *$ in this case allows us to state:

Proposition 2: Assume $p=1 / n$ where $n>1$. If $S B_{I}^{*}>0$, then $S B_{G}{ }^{*}>S B_{I}{ }^{*}$. However, if $S B_{I}^{*}<0$, then $S B_{G} *<0$. 
This says that if random punishment of a single individual yields net social benefits, then group punishment must yield strictly greater benefits. The reason for this counterintuitive result is that, if it is beneficial to punish one person chosen at random, then punishing everyone in the group must yield $n$ times the benefit. This reflects the fact the benefits of punishing the true offender are derived with certainty under group punishment but only with probability $1 / n$ under random punishment. However, if error costs are high enough to offset this benefit, then neither form of punishment is socially desirable.

These results show that there is a close correspondence between random punishment and group punishment. Although only one person is punished under the former strategy, all members of the group face an equal risk of punishment. In Section 6 we note several historical examples of this type of "punishment by lottery."

Finally, consider the impact of group size. In terms of the optimal fines, note that under both random individual punishment and group punishment, the optimal fine is decreasing in $n .^{14}$ This reflects the fact that under both strategies the likelihood of wrongful punishment is increasing in the size of the group. Total welfare is also decreasing in $n$ under both punishment strategies. ${ }^{15}$ Under individual punishment, an increase in $n$ raises the cost of maintaining a given apprehension probability, whereas under group punishment, it increases expected error costs. As a result, group size does not have a clear impact on the choice between the two strategies.

\subsection{The Optimal Strategy when $p$ is Variable}

\footnotetext{
${ }^{14}$ Specifically, $\partial F_{I} * / \partial n=\partial F_{G} * / \partial n=\sigma / B^{\prime \prime}<0$

${ }^{15}$ This follows by differentiating (6) - (8) with respect to $n$ and applying the Envelope Theorem when appropriate.
} 
We now turn to the case where $p$ is chosen optimally under individual punishment. From (1), the first order condition determining the optimal $p$ is

$$
B+\sigma F_{I}-c_{p}=0 .
$$

Together, (3) and (9) jointly determine $F_{I}{ }^{*}$ and $p$ in the general case. As noted above, $F_{I}{ }^{*}$ will be larger in this case compared to random punishment, assuming that $p^{*}>1 / n$. As for overall welfare, it must be larger when $p$ is chosen optimally than under random punishment. Thus, for a sufficiently effective detection technology, social welfare under individual punishment will exceed that under group punishment.

The impact of $n$ in this case is found by differentiating (3) and (9) to obtain:

$$
\frac{\partial F_{I}^{*}}{\partial n}<0, \quad \frac{\partial p^{*}}{\partial n}<0 .
$$

Thus, both the optimal fine and probability of apprehension are decreasing in the size of the group. These results reflect the higher expected error cost and higher marginal cost of apprehension as the group gets larger.

\subsection{Implications for Deterrence}

Although we have assumed that the optimal punishment strategy was chosen based on ex post concerns about fairness and the avoidance of error costs, the form of punishment actually chosen will nevertheless have implications for deterrence, assuming that offenders are rational. To examine this question, assume that there is a single potential offender in the group who weighs the monetary gain from committing the offense, $g$, against the expected punishment, given the punishment strategy that the 
enforcement authority is known to employ. ${ }^{16}$ Further, suppose that $g$ is a random variable with distribution function $Z(g)$, where $Z^{\prime} \equiv z$.

It follows that greater deterrence is achieved by the strategy that has the higher expected fine. Thus, the comparison is between $F_{G}$ under group punishment and $p F_{I}$ * under individual punishment. The above results immediately imply

Proposition 3: When individual punishment is random, $F_{G} *>p F_{I} *=F_{G} * / n$, implying that group punishment achieves greater deterrence. However, when $p$ is chosen optimally, $p^{*>1 / n}$ and $F_{I} *>F_{G} *$, in which case $p^{*} F_{I} * \frac{\geq}{<} F_{G} *$. Thus, either form of punishment may achieve more deterrence.

Group punishment achieves greater deterrence compared to random punishment simply because, given equal fines, the offender faces punishment with certainty under group punishment. However, this inherent advantage of group punishment regarding deterrence is mitigated when $p$ is chosen optimally because the fine under individual punishment is raised above that under group punishment and $p^{*>} 1 / n$. Thus, the expected fine may be larger or smaller than $F_{G}{ }^{*}$. The effect of an increase in the group size reduces deterrence under both strategies since we have shown that $F_{G}{ }^{*}$ and $p^{*} F_{I}{ }^{*}$ are both decreasing in $n$, but, as with the comparison of welfare, it does not have a clear effect on the choice between them.

\section{Deterrence is the Goal}

\footnotetext{
${ }^{16}$ We assume that $g \equiv 0$ for all members of the group besides the potential offender.
} 
Standard economic models of law enforcement have focused on deterrence as the primary social objective in determining optimal punishment strategies (Becker, 1968; Polinsky and Shavell, 2000a). Thus, in this section we examine the choice between individual and group punishment based on a goal of deterrence rather than ex post fairness. (We continue to include the costs of wrongfully imposed punishment.) ${ }^{17}$ Note that the focus on deterrence requires the enforcement authority to be able to precommit to a punishment strategy, including both the choice between individual and group punishment, the optimal fine, and (when relevant) the probability of apprehension.

As in the discussion of deterrence in the previous section, we assume that there is a single potential offender in the group who compares the gain from the offense, $g$, to the expected cost, where $g$ is drawn from the distribution $Z(g)$, which is known to the enforcer. Also let $H$ be the (fixed) harm to society from the offense. All other variables are defined as above.

Under either punishment strategy, the potential offender takes a draw from the $Z(g)$ distribution and then commits the offense if the realized gain exceeds the expected punishment costs. Thus, under individual punishment, the offender commits the offense if and only if $g \geq p F_{I}$. Expected social welfare is therefore given by ${ }^{18}$

$$
S B_{I}=\int_{p F_{I}}^{\infty}\left[g-H-(1-p) \sigma F_{I}\right] d Z(g)-c(p, n)
$$

Under group punishment, the offender commits the offense if and only if $g \geq F_{G}$, resulting in expected social welfare equal to

\footnotetext{
${ }^{17}$ Polinsky and Shavell (2000b) and Miceli (1991) examine hybrid models that consider both fairness and deterrence. We focus on a pure deterrence model here in order to make the distinction from the model in the previous section transparent.
} 


$$
S B_{G}=\int_{F_{G}}^{\infty}\left[g-H-(n-1) \sigma F_{G}\right] d Z(g)
$$

As above, we begin with the case where $p$ is fixed.

\subsection{The Optimal Strategy when $p$ is Fixed}

The optimal fine under individual punishment solves the first order condition

$$
-\left[p F_{I}-H-(1-p) \sigma F_{I}\right] z\left(p F_{I}\right) p-\left[1-Z\left(p F_{I}\right)\right](1-p) \sigma=0 .
$$

Likewise, the optimal fine under group punishment solves

$$
-\left[F_{G}-H-(n-1) \sigma F_{G}\right] z\left(F_{G}\right)-\left[1-Z\left(F_{G}\right)\right](n-1) \sigma=0 .
$$

In both cases, the marginal benefit of a higher fine in terms of the benefits of deterring one more crime equals the marginal increase in expected error costs. Consider first the special case of $p=1 / n$, random punishment. In this case, (13) becomes

$$
-\left[\left(F_{I} / n\right)-H-(n-1) \sigma\left(F_{I} / n\right)\right] z\left(F_{I} / n\right)-\left[1-Z\left(F_{I} / n\right)\right](n-1) \sigma=0
$$

Comparing (14) and (15) yields the following result:

Proposition 4: Assume $p=1 / n$, where $n>1$. Then $F_{I}^{*}=n F_{G}{ }^{*}$, or, equivalently, $p F_{I}^{*}=F_{G}{ }^{*}$.

Thus, when deterrence is the primary social goal, the optimal fine under individual punishment is scaled up so that it results in the same level of deterrence as group punishment. This reflects the fact that deterrence requires potential offenders to face the correct expected fine. This is in contrast to the case where fairness was the primary goal, in which case we showed that the optimal fines were equal.

\footnotetext{
${ }^{18}$ This form of social welfare assumes, as is typical, that the gains to the offender should be counted as social gains. While somewhat controversial, we retain this assumption in order to facilitate comparison of
} 
Substituting the optimal fines into (11) and (12) (and recalling that $c(1 / n, n)=0$ ) immediately yields

Proposition 5: When deterrence is the primary social goal, random individual punishment and group punishment yield equal expected social benefits.

Again this is in contrast to the case under a goal of fairness, where group punishment yielded greater social benefits than random punishment.

Changes in group size do not affect the equivalence of the two punishment strategies, though as above, increases in $n$ lower social welfare under both strategies for the same reasons. The optimal fine under group punishment varies ambiguously with $n$. On the one hand, larger $n$ lowers the optimal fine because of the higher error costs per dollar of the imposed fine, but on the other, larger $n$ raises the optimal fine because the increased deterrence lowers the expected number crimes and hence the expected number of wrongful punishments. The ambiguity here is due to the second effect, which was not present in the model based on fairness. The effect of $n$ on the optimal individual fine (under random punishment) is also ambiguous since $F_{I}{ }^{*}=n F_{G} *$. However, if the direct effect of $n$ is dominant, then $F_{I}^{*}$ will be increasing in the size of the group.

\subsection{The Optimal Strategy when $p$ is Variable}

The derivative of (11) with respect to $p$ is

$$
-\left[p F_{I}-H-(1-p) \sigma F_{I}\right] z\left(p F_{I}\right) F_{I}+\left[1-Z\left(p F_{I}\right)\right] \sigma F_{I}-c_{p}=0 .
$$

our results to the literature. See the discussion and references cited in Polinsky and Shavell (2000a, p. 48). 
This condition says that enforcement effort should be increased to the point where the marginal cost of increasing $p$ equals the net reduction in harm from the marginal offense plus the reduction in expected error costs for all offenses that are committed. Together, (13) and (16) jointly determine $F_{I}$ and $p$.

Note that since we showed above that welfare was the same under the two punishment strategies when $p=1 / n$, it must be true that when $p$ is chosen optimally, individual punishment yields higher social welfare (assuming that $p *>1 / n$ ). Thus, we have

Proposition 6: When the primary benefit of punishment is deterrence and $p$ is chosen optimally under individual punishment, then individual punishment is preferred to group punishment.

At this point it is worth comparing optimal enforcement under individual punishment in the current model to previously established results from the standard (pure) deterrence model (Polinksy and Shavell, 2000a). The key difference here is the inclusion in social welfare of costs associated with wrongful punishment as captured by $\sigma>0$. This reflects the fact that someone is punished in the current model, and society bears a cost if it is not the true offender. ${ }^{19}$ This leads to two departures from the standard model. First, the optimal fine is not generally maximal (i.e., equal to the offender's wealth) as it is in the standard model. It would, however, be maximal in the current

\footnotetext{
${ }^{19}$ In contrast, it is not clear in the standard literature (as surveyed by Polinsky and Shavell (2000a)) whether anyone is punished if the true offender is not identified. That is, it is not clear whether $1-p$ represents the probability that no one is punished, or that someone is incorrectly punished. Here, it is clearly the latter. (Of course, this distinction does not matter if $\sigma=0$.)
} 
model if $\sigma=0$. To see why, assume $\sigma=0$ and set $F_{I}$ below the offender's wealth. Then by raising $F_{I}$ and lowering $p$ such that $p F_{I}$ remains fixed, welfare will increase because the first term in (11) will be unchanged (given $\sigma=0$ ), but $c(p, n)$ will fall. This proves that setting $F_{I}$ less than maximal cannot be welfare-maximizing. However, when $\sigma>0$, this reasoning does not apply because raising $F_{I}$ and lowering $p$ cause an increase in expected error costs. Thus, it will not generally be true that $F_{I}^{*}$ is maximal in the current model.

When $F_{I}^{*}$ is not maximal, condition (13), which determines the optimal fine, holds with equality at the optimum. This implies that

$$
p F_{I}-H<(1-p) \sigma F_{I}
$$

Since the right-hand side of (17) is positive, $p F_{I} \frac{\geq}{<} H$. This is again in contrast to the standard enforcement model with $\sigma=0$, where $p F_{l}<H$ at the optimum. Thus, in the pure deterrence model with no consideration of error costs, there is some underdeterrence at the optimum in the sense that the marginal crime imposes more costs on society than it yields in benefits to the offender. This is optimal because the marginal benefit of deterring one more crime must be balanced against the marginal cost of increasing $p$ to achieve greater deterrence. When error costs are taken into account, however (i.e., when $\sigma>0$ ), this conclusion does not necessarily hold because increasing $p$ yields a social benefit in terms of reducing marginal error costs. Thus, it cannot be determined whether $p F_{I}$ is larger or smaller than $H$ at the optimum.

\section{Extensions}

This section discusses several extensions of the analysis. 


\subsection{Use of Non-monetary Sanctions}

We first consider the impact of using non-monetary sanctions such as prison, warfare, or execution rather than fines. ${ }^{20}$ The key difference is that non-monetary sanctions are costly to impose. It turns out, however, that this change does not have a significant qualitative effect on our basic conclusions. To see this, let $s$ be the dollar value of the non-monetary sanction to the offender, and let $\alpha$ be a scaling factor that reflects the marginal social cost of $s$ to society (where $\alpha \gg 1$ if the cost to the offender is part of social costs, as is usually assumed). Thus, the social cost of imposing the sanction is $\alpha s$. In the fairness model, the social benefit of imposing the sanction continues to be $B(s)$, which has the same properties as above (though the value of $s$ that maximizes $B$ may be different), and the expected sanction for purposes of deterrence is $p s$.

Social welfare under the two strategies remains essentially the same as under the fine, except that the total cost of punishment is higher. Under individual punishment, it is given by

$$
[(1-p) \sigma+\alpha] s_{I}
$$

while under group punishment it is

$$
[(n-1) \sigma+n \alpha] s_{G} .
$$

Thus, the marginal cost of punishment is higher. The result is that the dollar-equivalent sanction will be lower than the optimal fine, but all other results are essentially unaffected. For example, in the special case where $p=1 / n$ (random punishment), (18) becomes

$$
[(n-1) \sigma+n \alpha] s_{I} / n .
$$


Thus, total costs under individual punishment are simply $1 / n$ times total costs under group punishment, as was true when the sanction was a fine. It follows that when fairness is the goal, group punishment is preferred over random individual punishment (assuming any punishment is desirable) and the sanctions are identical. Similarly, when deterrence is the goal, group and random punishment yield equal social benefits, and $s_{I}{ }^{*}=n s_{G}{ }^{*}$. It also continues to be true that individual punishment will tend to dominate in both cases if the detection technology is sufficiently effective.

The preceding has assumed that the marginal cost of punishment is constant as the group size increases. If marginal costs were instead increasing in $n$, as is perhaps true of imprisonment, this would tend to reduce the desirability of group punishment for larger groups. However, for other non-monetary sanctions, like warfare, there may be decreasing marginal costs (due to scale economies), which would give an advantage to group punishment as group size increases.

\subsection{Possibility that the Group will Turn Over the Offender}

One possible motivation for using group punishment is to give innocent members of the group an incentive to turn over the true offender (Levmore, 1995a). The difficulty with this "information extraction" rationale is that, while group members may have an incentive to turn someone over in order to avoid punishment, they do not necessarily have an incentive to turn over the guilty party. Thus, absent independent evidence, it is not clear that the outcome in this case is different from that under random punishment, which we have seen is inferior to group punishment in terms of fairness, and equivalent in terms of deterrence.

\footnotetext{
${ }^{20}$ The usual economic motivation for imposing non-monetary sanctions is that offenders might have insufficient wealth to pay the fine (the so-called judgment proof problem) (Polinsky and Shavell, 2000a).
} 
Suppose for the moment, though, that the group's revelation is believable. (For example, suppose the enforcer requires the group to simultaneously turn over evidence of the offender's guilt.) Then we might capture this aspect of group punishment by defining a function $q\left(F_{G}\right)$, which is the probability that the group will turn over the offender when each member of the group is threatened with a fine of $F_{G}$. While abstracting from the details of the group's decision making, it seems reasonable to assume that $q>0$, or, the larger is the group sanction, the more likely it is that the group will turn over the offender. $^{21}$

In this formulation of group punishment, social welfare under the fairness and deterrence versions of the model, respectively, are given by

$$
\begin{aligned}
& S B_{G}=q\left(F_{G}\right) B\left(F_{T}\right)+\left(1-q\left(F_{G}\right)\right)\left[B\left(F_{G}\right)-(n-1) \sigma F_{G}\right] \\
& S B_{G}=\int_{f}^{\infty}\left[g-H-\left(1-q\left(F_{G}\right)\right)(n-1) \sigma F_{G}\right] d Z(g),
\end{aligned}
$$

where $F_{T}$ is the fine imposed on an offender turned over by the group, and $f=q F_{T}+(1-q) F_{G}$ is the expected fine a potential offender faces. ${ }^{22}$ Not surprisingly, the possibility that the group will turn over the offender enhances the desirability of group punishment in both versions of the model. It continues to be true, however, that individual punishment is preferred over group punishment in both models if the detection technology is sufficiently accurate, though the required level of accuracy is higher than in the case where $q \equiv 0$. Thus, the possible information extraction function of group punishment is most appealing when evidence gathering is difficult.

\footnotetext{
${ }^{21}$ It is not clear how $q$ would vary with $n$. Smaller groups may be more reluctant to turn over one of their own, but offenders may find it easier to remain anonymous in large groups. A formal model of group decision making would be necessary to resolve this issue.

${ }_{22}$ Obviously, these expressions reduce to (2) and (12), respectively, when $q=0$.
} 


\subsection{Possibility that the Offender will Turn Himself In}

Another possible rationale for group punishment is that the offender might be induced to turn himself in, presumably in hopes of receiving a more lenient punishment than he would otherwise receive under the optimal policy. ${ }^{23}$ Of course, the same possibility exists under individual punishment. To illustrate, let $F_{j}^{s}$ be the fine imposed on an offender who turns himself in under enforcement strategy $j=I, G$. Incentive compatibility requires that $F_{I}^{s} \leq p F_{I}$ under individual punishment (assuming risk neutrality of the offender), and $F_{G}{ }^{s} \leq F_{G}$ under group punishment. ${ }^{24}$ To the extent that offenders are rational and choose to confess, this scheme improves welfare under both punishment strategies and under both social objectives by reducing error costs, and, in the case of individual punishment, enforcement costs. ${ }^{25}$ It does not, however, give an obvious advantage to either punishment strategy, and hence is not a clear rationale for threatening group punishment (unless the offender is known to suffer disutility when members of his group are wrongfully punished, as may be true, for example, when the group is a family).

\subsection{The Impact of the Offender's Risk Preference}

We have followed the literature in assuming that potential offenders are risk neutral, but in the current context, the risk preferences of the offender may affect the choice between the two punishment strategies in two ways. First, if the offender is risk averse, then individual punishment will result in greater deterrence than group punishment, all else equal, because individual punishment is uncertain. ${ }^{26}$ In contrast, if

\footnotetext{
${ }^{23}$ Levmore (1995a) discusses this motivation for group punishment and proposes an incentive compatible scheme along the lines described here.

${ }^{24}$ Note the analogy to plea bargaining in criminal prosecution.

${ }^{25}$ A further benefit in the fairness model is due to the fact that $B\left(p F_{I}\right)>p B\left(F_{I}\right)$ given the concavity of $B$.

${ }^{26}$ Specifically, if $p F_{I}=F_{G}$, the offender's utility under group punishment will be greater than his expected utility under individual punishment, assuming diminishing marginal utility of income.
} 
the offender is risk loving (as is sometimes claimed about criminals (Becker, 1968)), then the reverse will be true. Second, risk averse offenders will be more willing to turn themselves in under individual as compared to group punishment, whereas risk averse offenders will be less inclined to do so.

\section{Examples of Group Punishment}

This section discusses several examples of group punishment in light of the theory. The discussion is not meant to be exhaustive but merely illustrative of the scope of group punishment schemes, both historically and in modern law enforcement.

\subsection{Ancient Examples}

Posner (1983: pp. 193-195) notes that one of the defining characteristics of primitive law enforcement is its reliance on collective, or group responsibility. If a person harmed another, primitive law allowed the victim's kinsmen to seek compensation from the injurer or any of his kinsmen, and if they refused to pay, to retaliate against the injurer or his kinsmen. Even a state as advanced as ancient Greece believed that a murderer "polluted" his city and his family, creating a form of collective guilt that extended to the murderer's descendants (Posner, 1983: p. 217). Of course, the most famous example is the pollution of Thebes caused by Oedipus's murder of his father. ${ }^{27}$

The Bible, especially the Old Testament, is also replete with various examples of group responsibility in ancient society. The stories of Noah's flood ${ }^{28}$ and Sodom and Gomorrah $^{29}$ dramatically portray the notion that the sins of some pollute an entire

\footnotetext{
${ }^{27}$ A more modern example is found in the work of Nathaniel Hawthorne, which similarly evinces "the theme that the sins of the father are visited upon the children" (Buel, 1986, p. 360).

${ }^{28}$ Genesis, 7

${ }^{29}$ Genesis, 19.
} 
community for which the guilty and innocent alike must pay. (Of course, if all citizens of these communities were sinners, then these are not true examples of group punishmentthe stories are not specific on this point.)

An example of random punishment is found in the story of Jonah. ${ }^{30}$ The story begins with Jonah boarding a ship to escape God's command to go to the wicked city of Nineveh to serve as a missionary. To punish Jonah's defiance, God creates a severe storm that threatens to destroy the ship and all its crew. The mariners therefore cast lots to detect the person whose transgression brought about the storm, and when Jonah is miraculously identified as the guilty party, the mariners throw him overboard. The fact that Jonah was correctly identified by the lottery (obviously through divine intervention) can only be seen as legitimizing this type of punishment in the eyes of readers.

The New Testament story of Herod's attempt to locate and kill the baby Jesus is perhaps the most extreme Biblical example of group punishment. ${ }^{31}$ After learning of the birth of the King of the Jews in the vicinity of Bethlehem, Herod first attempted to locate the child by sending the wise men. When that "individual punishment" strategy failed, he ordered the slaughter of all children less than two years of age in the region. This story is a good illustration of the attractiveness of group punishment when detection is difficult and punishment of the innocent is not seen as costly. It is more likely, however, that the story was meant to be interpreted as a critique of this particularly hash form of group punishment, reflecting the transition to a more modern view of punishment.

Our final example of group punishment in ancient law is found in the Hammurabi Code (Levmore, 1995b: p. 117), which provided that a victim of robbery, if unable to

\footnotetext{
${ }^{30}$ Jonah, 1:1-15.

${ }^{31}$ Matthew, 2:1-16.
} 
identify the guilty party, could collect compensation from the city in which the robbery occurred. Likewise, the kinsmen of a murder victim could seek compensation from the city in which the murder occurred. A similar provision existed in old English law as chronicled by Blackstone in his Commentaries. In particular, the residents of a village in which a man was robbed were obliged to "make hue and cry after the felon," and if they failed to locate him, were collectively liable for "damages equivalent to his loss." These examples also signal a transition from ancient to modern practices in their emphasis on "compensation" of victims rather than "punishment" of injurers. We pursue this point in the next section.

On a theoretical level, the pervasiveness of group punishment in ancient society can be explained based on two characteristics of primitive law enforcement: the concept of punishment as revenge (Holmes, 1881: p. 6; Posner, 1983: Chapter 8), and the lack of a specialized (state run) police force with a monopoly on law enforcement. In terms of the model, these characteristics suggest that the primary social objective was fairness, or proportionality of punishment ("an eye for an eye"), and that the technology of detection was ineffective or non-existent, both of which we showed are necessary conditions for group punishment to be preferred to individual punishment.

\subsection{Modern Examples}

To modern sensibilities, the greatest objection to group punishment is the punishment of the innocent along with the guilty. Nevertheless, modern examples of group responsibility are more pervasive than conventional wisdom suggests (Levmore, 1995b). In contrast to primitive society, however, they tend to involve situations where

\footnotetext{
${ }^{32}$ Commentaries, Book III, Chapter 9, p. 161.
} 
"innocent" members of the group are in some sense culpable, or, what amounts to the same thing, where the cost of punishing the innocent is not seen as being high.

An example of the first type of situation is the imposition of sanctions, or the waging of warfare, against countries harboring terrorists. ${ }^{33}$ As Levmore (1995b: p. 99) notes that "We are accustomed to the fact that war claims the lives of innocent people," and "one nation may be justified in warring against another when the other nation is unable to control the actions of some of its inhabitants." Another military example of a different sort is the execution by lottery of soldiers in companies that broke during combat, a form of discipline employed by the Italian army during WW I (Gooch, 1996). In both cases, there is a sense in which members of the group besides the guilty party are at least somewhat culpable, and that group punishment is both an effective way to induce them to reveal the culprit's identity and to deter future offenses.

As suggested above, however, group responsibility in modern society more typically involves situations where the goal is compensation of victims rather than punishment of offenders. In such situations, which are more reflective of tort law than criminal law, ${ }^{34}$ imposition of liability on someone other than the responsible party is not seen as imposing a large social cost, and indeed is often an effective way to achieve the goal of deterrence. Examples include various forms of vicarious liability like the doctrine of respondeat superior, under which an employer can be held responsible for torts committed by his employees; the related criminal law rule that corporations may be held

\footnotetext{
${ }^{33}$ Such actions are not without precedent in history. A famous ancient example was the sack of Troy by the Greeks in retaliation for the kidnap of Helen, which archeologists have shown was likely an historical event (Wood, 1998).

${ }^{34}$ Primitive society did really draw a distinction between torts and crimes, primarily because there did not exist a state to carry out criminal enforcement (Posner, 1983: Chapter 7).
} 
criminally liable for crimes committed by employees; ${ }^{35}$ and joint and several liability, under which any one of a group of injurers can be held liable for the victim's entire loss regardless of their particular contribution. ${ }^{36}$ These forms of liability promote deterrence when offenders are out of reach of victims or law enforcers, and those subject to liability are in a position to monitor their actions (Varian, 1990).

A famous tort case provides a concrete example of the court's willingness to use group punishment in this context. In Ybarra v. Spangard, ${ }^{37}$ the court ruled that a patient injured during an operation could jointly collect from several health professionals for the negligence of one of them. This case reflects a general class of torts in which courts apportion damages in the presence of uncertainty over causation (Shavell, 1985), but it is unique in an important respect - the members of the group in this case presumably knew the identity of the negligent party but were reluctant to reveal that information. The threat of group punishment in such a setting may therefore be an effective way to encourage monitoring of precaution before the fact (thus promoting deterrence) and revelation of information after the fact (thus saving on detection costs).

Levmore (1995a) suggests that a better ruling in such a case might have been to threaten each of the defendants with liability in excess of the victim's damages unless the responsible party was identified. Compared to the sharing rule of Ybarra, Levmore argues that this "overextraction rule" has the twin virtues of enhancing the incentives of innocent members of the group to turn in the offender, ${ }^{38}$ and giving the offender an incentive to confess. The obvious disadvantage is that it entails especially high error

\footnotetext{
${ }^{35}$ As Garoupa (2000, p. 244) notes, "Within the context of corporate liability, shareholders become quasienforcers."

${ }^{36}$ As Menell (1991: p. 109) notes, under joint and several liability, "disposal of a thimbleful of hazardous waste at a large disposal site exposes an entity to enormous potential liability."
} 
costs if neither of these outcomes occurs. ${ }^{39}$ The proposal is therefore not a practical one, but it nevertheless helps bring into focus the trade-off involved in the use of group punishment schemes.

\section{Conclusion}

This paper has examined the choice between individual and group punishment when the enforcement authority is uncertain about the offender's identity but knows he is a member of a well-defined group. We considered this choice in the context of two social objectives: ex post fairness of punishment and deterrence. The results of the theoretical analysis showed that when fairness is the goal and the enforcer cannot invest in detection, group punishment is preferred to individual (random) punishment (assuming punishment is desirable). However, the possibility of investing in detection raises the payoff from individual punishment both by increasing the fairness benefits of punishment and reducing the likelihood of error costs. If strong enough, these effects make individual punishment preferable.

When deterrence is the main goal of punishment and the enforcer cannot invest in detection, individual and group punishment yield equal social benefits. However, when the enforcer can invest in detection, individual punishment is again preferred.

Our survey of various examples of group punishment suggested that these results broadly conform to the greater use of group punishment schemes in ancient times when detection was difficult and vengeance was the predominant objective of punishment. In

${ }^{37} 154$ P.2d 687 (Cal. 1944).

${ }^{38}$ Though it also likely increases the risk that they will misidentify him.

${ }^{39}$ For example, a rational offender might refuse to confess knowing that the enforcer will not actually carry out the threatened penalty (Levmore, 1995a, p. 1595). In other words, the policy is not time-consistent. 
contrast, improvements in the technology of law enforcement, aversion to punishing the innocent, and the shift in emphasis toward deterrence are consistent with the modern reliance on individual punishment. This is not to say the group punishment is nonexistence in modern society. As we saw, however, modern examples are more subtle than in ancient times and tend to be used in civil as opposed to criminal law settings where compensation of victims is important, and severing the link between punishment and responsibility is not seen as overly costly. 


\section{References}

Becker, G. (1968) "Crime and Punishment: An Economic Approach,” Journal of Political Economy 76: 169-217.

Blackstone, W. (1766) Commentaries on the Laws of England.

Buel, L. (1986) New England Literary Culture, Cambridge: Cambridge Univ. Press.

Garoupa, N. (2000) "Corporate Criminal Law and Organization Incentives: A Managerial Perspective," Managerial and Decision Economics 21: 243-252.

Gooch, J. (1996) "Morale and Discipline in the Italian Army, 1915-1918," in H. Cecil and P. Liddle, eds., Facing Armageddon, London: Leo Cooper.

Govindasamy, R., J. Herriges, and J. Shogren (1994) "Nonpoint Tournaments," in C. Dosi and T. Tomasi, eds., Nonpoint Source Pollution Regulation: Issues and Analysis, Dordecht: Kluwer Academic Publishers.

Harris, J. (1970) “On the Economics of Law and Order," Journal of Political Economy 78: $165-174$.

Holmes, O. W. (1881) The Common Law, Boston: Little-Brown.

Holmstrom, B. (1982) "Moral Hazard in Teams," Bell Journal of Economics 13: 324340.

Levmore, S. (1995a) "Gomorrah to Ybarra and More: Overextraction and the Puzzle of Immoderate Group Liability," Virginia Law Review 81: 1561-1604

(1995b) "Rethinking Group Responsibility and Strategic Threats in Biblical Texts and Modern Law," Chicago-Kent Law Review 71: 85-121.

Menell, P. (1991) "The Limitations of Legal Institutions for Addressing Environmental Risks," Journal of Economic Perspectives 5: 93-113.

Miceli, T. (1991) "Optimal Criminal Procedure: Fairness and Deterrence," International Review of Law and Economics 11: 3-10.

Polinsky, A. M. and S. Shavell (2000a) "The Economic Theory of Public Enforcement of Law," Journal of Economic Literature 38: 45-76.

(2000b) "The Fairness of Sanctions: Some Implications for Optimal Enforcement Policy," American Law and Economics Review 2: 223-237.

Posner, R. (1983) The Economics of Justice, Cambridge: Harvard Univ. Press. 
Rasmusen, E. (1987) "Moral Hazard in Risk Averse Teams," Rand Journal of Economics 18: 428-435.

Segerson, K. (1988) "Uncertainty and Incentives for Nonpoint Pollution Control," Journal of Environmental Economics and Management 15: 87-98.

Shavell, S. (1985) "Uncertainty Over Causation and the Determination of Civil Liability," Journal of Law and Economics 28: 587-609.

Varian, H. (1990) "Monitoring Agents with Other Agents," Journal of Institutional and Theoretical Economics 46: 153-174.

Wittman, D. (1974) "Punishment as Retribution," Theory and Decision 4: 209-237.

Wood, M. (1998) In Search of the Trojan War, Berkeley, CA: Univ. of California Press.

Xepapadeas, A. (1991) "Environmental Policy Under Imperfect Information: Incentives and Moral Hazard," Journal of Environmental Economics and Management 20: 113-126. 